\title{
The colour green in public procurement
}

\author{
B. Orgiano \\ DICAAR - Department of Civil Engineering, Environmental Engineering \\ and Architecture, University of Cagliari, Italy
}

\begin{abstract}
This study aims to analyze how energetic efficiency can be included inside the phases of public procurement, since its beginning, with particular reference to the public procurement for existing buildings.

This sector, despite the actual economic crisis, continues to maintain consistent dimensions and to move huge economic resources involving various sectors of market. Environment health cannot remain out of the factors considered in this circle and more and more we are invited from European Community to have a green approach also in this sector.

In fact, if before the European Community Directives aimed to guarantee the general principles of free competition, impartiality, no discrimination and transparency, today the further aim is to improve this old approach, to come to another one based on energetic efficiency aspects, that leads towards goods and respectful services to the environment, social responsibility and innovation.

This task, through the study of the European and Italian laws for public procurement, wants to investigate the causes that have led to the birth and development of the concept of 'green public procurement', trying to trace its route and analyzing its different applications in Europe, but, above all, in Italy. Public procurement will be analyzed, focusing on the ones that have as their object existing buildings, to try to formulate green rules to include in public announcements since the beginning.
\end{abstract}

Keywords: green public procurement, energy efficiency, building retraining.

\section{Introduction}

Despite the actual crisis and the bending of the markets, public procurement continues to maintain consistent dimensions and to move huge economic resources involving various sectors of the market. 
Environmental matter cannot remain out of the variables considered in such circles and more and more we are pushed to a 'green' approach also in this sector.

In fact, if at the beginning the European Directives aimed to guarantee the general principles of free competition, impartiality in treatment, no discrimination and transparency, today the further aim is to improve and modernize the draft legislative acts to come to a more balanced politic, which can sustain with great success supply and demand, giving suitable and respectful services for the Environment and in the meantime being also socially responsible and innovative.

So, the operators involved in public procurements and in the whole productive cycle will be certainly called to upgrade themselves and for a professional and technological modernization, because, with the development of the green public procurement principles, the new requirements for the competition demanded by Public Administration will be higher than the past.

This task is established to study how Public Administration today picks out green award criteria for the evaluation of tenders that, according to the 'most economically advantageous tender' rule will allow the procurement commission to assess the real most economically advantageous tender, according to the 'green' award criteria indicated in the official contract notice.

\section{The choice of the colour green}

When we talk about public procurements, we always imagine them as very long processes that will develop over a very long time through the following steps.

That's why it can be good to adopt a new different approach to the matter, considering the Environmental aspects since the beginning, trying to identify what our aim is and how we can get it.

In fact, today we have to think of the consequences of our actions on life on the whole planet, much more than the past.

We MUST do it! For us, our children and future population.

If we take a look at the international contest, we can see that the environment matter is very real today and each country has to make important choices every day in order to improve its economy, but, at the same time, to respect the environment.

Looking at the European level, we can say that the green approach has been approved in a huge number of EU policies and strategies concerning public procurement and this fact encourages a more sustainable use of natural resources and it sets up behavioural changes for sustainable consumption and production.

Also in Italy many paths have been taken in this sector, but many others have to be made in the future.

\section{The importance of retraining public existing buildings}

We can say that for the public procurement related to buildings that do not yet exist $[1,2]$ we have available many rules and parameters that drive us toward more effective planning, but we cannot say the same for public procurement related to existing buildings [3]. 
In this particular case, we are speaking about public existing buildings, because in our Country they are very consistent and we have to give particular attention to all of them, which are still used as offices and representative institutional places, but certainly they can't give very efficient energy performances [4]; that's why we have to evaluate what kind of energy performances these buildings give us today and how we can improve them, looking for the best solution for getting much more high energy performances after the action.

So, public properties must be considered in order to maintain their important part in the contemporary set of public existing buildings that we still need and we still want to use. That is why today energy retraining [5] appears as the main item on which we have to focus and it must be considered for the public plans of future actions, because in this way we could not only get sure benefits from the environmental and energy point of view (our priority), but also from the social and economic one [6]. In fact, improving traditional energy production systems with new ones appears today as the best way to obtain good results in the energy sector and it also represents a good example for the community [7].

Furthermore, we also have to consider these aspects from the historical and cultural point of view, because our artistic heritage is very rich and many of our historical existing buildings are used for entertaining in their inner offices and for public institutional activities, even if they are not able to guarantee efficient energy performances [8], because they were built with different technical systems, so various compared to the actual ones [9].

All of these considerations are placed very well inside the international context [10], where the debate around these themes is more and more common.

In fact, today the attention for energy performances is higher than in the past, as well as the problem of emissions of greenhouse gases and of other pollutant emissions in the atmosphere and the consequential climate change mitigation. As is well-known, these factors will have negative consequences in the middle and long term and we have to control them and evaluate how we can reduce them to guarantee the best possible quality of life on our Planet.

It has been almost two decades that we daily listen to people speaking about global warming, both from the main experts and from the average people.

As history teaches us, at the beginning the theories about these matters were ignored, more or less consciously, while today the problem is universally recognized and we can appreciate that it is internationally discussed.

For these reasons, considering that the existing public 'old' buildings represent a huge set of actions, we must consider the environmental consequences of their use and energy low-performances as the initial point of our planning activity, to try to adopt a green approach to the problem, to find efficient solutions available for now and during the whole life of the buildings to allow them to provide energy high-performances.

\section{Route structure}

As is known, one of the most important aims of the Kyoto Protocol is the reduction of greenhouse gases and of other pollutant emissions in the atmosphere and the 
consequential climate change mitigation, to try to stop the global warming phenomenon.

To try to improve the existing buildings energy efficiency is considered as one of the most important measures to reach this aim.

In fact, as we said before, the very huge quantity of existing public 'old' buildings seems to be mainly responsible for actual high energy consumption, which is characterized by massive fossil fuel use and this leads to a considerable impact on the environment.

So, we have to focus our attention on these existing 'old' buildings, analyzing their actual energy performances and evaluating how much we spend every year to manage them.

To study every building in particular would be the best way of studying these aspects, but, because of the the huge number of these buildings, this could be difficult to do, above all from the temporal point of view. Moreover, the aim of this study is to try to define some green criteria that we can use generally in all public procurement in which retraining in existing public buildings is involved.

In fact, today, in Italy, we have just put the attention on minimal environmental criteria for public procurement of many categories of supplies, but for works and services (in term of design) we still have a lot of work to do!

So, the aim of this study is to try to decide which kind of green criteria we can consider and include in public announcements for works and services (above all, design) and see if it is possible to apply them in some existing cases, to see how they work.

\section{Action steps}

Step 1: knowing the initial context.

- $\quad$ Picking out the state of the art for European and Italian legislation in the matter of public procurement and new directions to preserve environmental health;

- $\quad$ Studying in detail the evolution of GPP (green public procurement) [11] to see its application, in Europe and Italy;

- Analyzing the positive/negative consequences of these proceedings.

Step 2: data processing.

- Organizing our data on territorial GIS cartography, to create maps to know what are the main leader countries currently using GPP policies;

- $\quad$ editing schemes and charts to pick out actual conditions.

Step 3: aim actions.

- Picking out one or more public announcements for works or services (design) and studying them to insert green criteria for tendering;

- $\quad$ Simulating different scenarios for different works and services and test our green criteria, to see if they are good and work properly.

Step 4: final documents.

- Collecting maps of the investigated areas and the public announcements we have considered;

- $\quad$ Seeing what the results are and group them into negative or positive; 
- $\quad$ Picking out our green criteria and, in general, the green approach we used in the research.

\section{Conclusions.}

It is known that, despite the actual economic crisis, the public procurement sector continues to maintain consistent dimensions and to move huge economic resources involving various sectors of the market.

This is true for works, supplies and services.

For the environment, the consequences of our actions have today to be monitored and checked in a very efficient way, because we have a moral obligation to save the planet.

Considering the importance of public procurement, we MUST also include in our economical proceedings green thoughts. That is why the aim of this study is to fix and share a cognitive picture of the actual situation for public procurement of works, supplies and services, and improve it with several proposals, above all for works and services (design), that in Italy still represents today the less considered aspects in this matter.

All the collected data will be organized into charts and thematic maps, because only in this way will the representations of the actual state be more immediate and easy to read; so, we will able to appreciate what will be the best efficient actions for us, based on a real priority and on more concrete specific plans.

With a similar tool in its hands, Public Administration will again be the main actor in the decisional show about future plans and it will become the director of the activities, having already studied the situation it will be able to give more specific public notice for future plans.

Furthermore, one of the most important advantages we can take from this job is that all the operators involved in the procurement cycle (contractors, engineers, architects and designers in general) will have to upgrade their studio's structure and improve their own expertise, to become more competitive in making their tenders for a specific public announcement.

In this way, Public Administration will also have huge advantages. In fact, it will have both the possibility to experiment with this green criteria [12] in public procurement for retraining its own existing real estate patrimony, developing an exemplary role for the community (as required by the Directive 2012/27/UE, artt. 4 and 5), and, from the other side, it will be the first one that will reap benefits from a significant economic saving, due to this more specific way of planning actions and to the important energy performance costs reduction of its own existing real estate patrimony, which is still active.

\section{References}

[1] Bazzini G., Cellai G., Gai M. (2007), Le prestazioni energetiche degli edifici, Maggioli Editore, Santarcangelo di Romagna (RN).

[2] Cammarata G., Cammarata M., D’Amico G., Russo F. (2013), Edifici quasi zero energia, Grafill, Palermo. 
[3] Grassi W., Scatizzi G., Venturelli F. (2007), La certificazione energetica degli edifici e degli impianti, Maggioli Editore, Santarcangelo di Romagna (RN).

[4] Direttiva 2012/27/UE del Parlamento Europeo e del Consiglio del 25 ottobre 2012 sull'efficienza energetica (che modifica le Direttive 2009/125/CE e 2010/30/UE e abroga le Direttive 2004/8/CE e 2006/32/CE).

[5] Direttiva 2014/24/UE del 26 febbraio 2014 sugli appalti pubblici (che abroga la Direttiva 2004/18/UE).

[6] Enea (2010), Rapporto Energia e Ambiente 2009. Analisi e scenari, Ente per le Nuove tecnologie, l'Energia e l'Ambiente, Roma.

[7] www.avcp.it

[8] www.ec.europa.eu

[9] www.enea.it

[10] www.eur-lex.europa.eu

[11] www.gppinfonet.it

[12] www.minambiente.it 